\title{
Assessing the proxy response bias of EQ- 5D-3 L in general population: a study based on a large-scale representative household health survey using propensity score matching
}

Ying Liang ${ }^{1,2 \dagger}$, Tianle Che ${ }^{1,2+}$, Haiyue Zhang ${ }^{1,2+}$, Lei Shang ${ }^{1,2}$, Yuhai Zhang ${ }^{1,2}$, Yongyong X $\mathbf{u}^{1,2}$, Lingxia Guo $^{3}$ and Zhijun $\operatorname{Tan}^{1,2^{*}}$

\begin{abstract}
Background: Proxy respondent-someone who assists the intended respondent or responds on their behalf-are widely applied in the measurement of health-related quality of life (HRQL). However, proxies may not provide the same responses as the intended respondents, which may bias the findings.

Objectives: To determine whether the use of proxies is related to socio-demographic characteristics of the intended respondent, and to assess the possible proxy response bias of Chinese version of EQ-5D-3 $\mathrm{L}$ in general population.

Methods: A cross-sectional study based on a provincially representative sample from 2013 National Health Service Survey (NHSS) in Shaanxi, China was performed. HRQL was measured by Chinese version of EQ-5D-3 L. Propensity score matching (PSM) was used to get matched pairs of self-reports and proxy-reports. Before and after PSM, univariate logistic and linear models including the indicator of proxy response as the only independent variable, were employed to assess the possible proxy response bias of the dimensional and overall health status of EQ-5D-3 $\mathrm{L}$ respectively.

Results: $19.9 \%$ of the responses involved a proxy. Before PSM, the proxy-report group was younger in age and reported less unhealthy lifestyle, lower prevalence of disease, and less hospitalization than the self-report group. After PSM, it showed that the proxy-report group was statistically more likely to report health problem on each dimension of EQ-5D-3 L, with odds ratios larger than one comparing with self-report group. The means of EQ-5D-3 L index and EQ VAS of proxy-report group were 0.022 and 0.834 lower than self-report group.

\footnotetext{
* Correspondence: tanzifmmu@126.com

${ }^{+}$Ying Liang, Tianle Che and Haiyue Zhang contributed equally to this work. 'Department of Health Statistics, Fourth Military Medical University, Xi'an,

Shaanxi Province, China

${ }^{2}$ Ministry of Education Key Lab of Hazard Assessment and Control in Special

Operational Environment, Fourth Military Medical University, Xi'an, Shaanxi

Province, China

Full list of author information is available at the end of the article
}

(c) The Author(s). 2020 Open Access This article is licensed under a Creative Commons Attribution 4.0 International License, which permits use, sharing, adaptation, distribution and reproduction in any medium or format, as long as you give appropriate credit to the original author(s) and the source, provide a link to the Creative Commons licence, and indicate if changes were made. The images or other third party material in this article are included in the article's Creative Commons licence, unless indicated otherwise in a credit line to the material. If material is not included in the article's Creative Commons licence and your intended use is not permitted by statutory regulation or exceeds the permitted use, you will need to obtain permission directly from the copyright holder. To view a copy of this licence, visit http://creativecommons.org/licenses/by/4.0/. The Creative Commons Public Domain Dedication waiver (http://creativecommons.org/publicdomain/zero/1.0/) applies to the data made available in this article, unless otherwise stated in a credit line to the data. 
(Continued from previous page)

Conclusions: Significantly negative proxy response bias was found in Chinese EQ-5D-3 L in general population, and the magnitude of the bias was larger in physical dimensions than psychological dimensions after using PSM to control confounders.

Keywords: Proxy response bias, Health-related quality of life, EQ-5D-3 L, Propensity score matching

\section{Introduction}

Health-Related Quality of Life (HRQL) is known as an important component of health evaluation in addition to conventional objective indicators, such as morbidity, mortality and clinical measurements [1-4]. In order to ensure adequate sample size and reduce the selection bias for the survey, proxies (e.g., family, professional caregiver, friend, relative) are usually allowed to substitute for the intended respondents who are unavailable (e.g., institutionalized or hospitalized) or unable (e.g., physical or cognitive impairments) to complete the questionnaire on their own behalf [5]. However, this may bring significant proxy response bias into HRQL measurement [5-9].

EQ-5D is a generic instrument widely applied for measuring HRQL and health technology assessment (HTA) in many countries [10-14]. In China Guidelines for Pharmacoeconomic Evaluations, one of the most important HTA guidelines in China, EQ-5D is one of the four recommended preferred outcome for QoL [15]. To date, extensive studies have assessed the inter-rater reliability between self-report and proxy-report EQ-5D [1628]. The inter-rater reliability is primarily measured using precision-the strength of agreement between proxy and patient responses, and bias-systematic difference in proxy response [29]. These existing studies primarily investigated the inter-rater reliability on specific population, such as children [19, 27], older adults [24, $27,28]$, dementia [16, 18, 21, 23-25], stroke [17], prolonged mechanical ventilation [20], intensive care [22], and vascular cognitive impairment [25]. In general, most of these studies showed that proxies were inclined to under-estimate the patients' health conditions, and proxy-reports and patient-reports did not agree and were inconsistent in terms of proxy type (e.g. spouse, relatives, or health professionals, etc.), observability of the domains or characteristics of the patients.

There are a number of limitations to the existing studies into proxy response bias in EQ-5D. The most important one is that most studies were done with paired proxy-patient populations, in which each intended respondent is paired with a proxy and both the proxy and the intended respondent report EQ-5D indicating that the proxies are not necessary, even though the proxy response bias might be "real". In practice, however, proxy responses are only necessary when the responses of the intended respondents are not available. To date, no studies in EQ-5D-3 L evaluated proxy response bias by using unpaired study design. Another important limitation is that most studies cover relatively small samples of population with specific health problems. But proxy response bias takes on great importance in large representative surveys, such as the Behavioral Risk Factor Surveillance System (BRFSS) [30, 31], and the National Health Interview Survey (NHIS) [32], from which the conclusion can be generalized to the general population, and are more valuable for decision-making in public health. In addition, small sample size is not sufficient to examine the incidence of proxy responses among different demographic groups, thus making it difficult to understand how often "real" proxy responses are needed and used.

Investigating the "real" proxy response bias of HRQL in a large representative survey can be complicated, because the actual health profiles of the intended respondents who uses proxy are not available. Studies have shown that HRQL is affected by numerous factors, such as age, marital status, health behavior, and chronic disease morbidity [33-38]. In order to accurately measure the proxy response bias of HRQL in a cross-sectional survey, many confounding factors must be controlled simultaneously. Propensity score matching (PSM) is a technique that usually applied to mimic randomized controlled trials (RCTs), which can minimize the bias caused by confounding factors, and similar results to RCTs can be obtained $[39,40]$, therefore PSM is applicable to address the limitations described above $[5,7,29]$.To date, there is no study investigating proxy response bias of the Chinese version of EQ-5D-3 L in general population. Based on a large representative survey of general population, this study has two objectives: (1) to determine whether the use of proxies is related to sociodemographic characteristics of the intended respondents; (2) to evaluate the presence, direction and magnitude of possible proxy response bias in the EQ-5D-3 $\mathrm{L}$.

\section{Methods \\ Data source \\ National Health Service Survey}

The National Health Services Survey (NHSS) is one of the most influential health survey in China $[41,42]$. The data was obtained from the 2013 National Health Services Survey (NHSS) in Shaanxi province, which has been conducted every 5 years since 2003. Now, it is one of the largest and influential health surveys in this area. The four-stage cluster unequal probability sampling method was used to select a provincially representative 
Table 1 Basic characteristic of the sample at baseline

\begin{tabular}{|c|c|c|c|c|}
\hline & $\begin{array}{l}\text { Total } \\
\mathrm{n}=(44134)\end{array}$ & $\begin{array}{l}\text { Proxy-report } \\
(n=8789)\end{array}$ & $\begin{array}{l}\text { Self-report } \\
(n=35,345)\end{array}$ & $P$ \\
\hline Household heads & $18,884(42.8)$ & $1698(19.3)$ & $17,186(48.6)$ & $<0.001$ \\
\hline \multicolumn{5}{|l|}{ Age (y) } \\
\hline $15-44$ & $18,282(41.4)$ & $5070(57.7)$ & $13,212(37.4)$ & \multirow[t]{3}{*}{$<0.001$} \\
\hline $45-64$ & $18,339(41.6)$ & $2216(25.2)$ & $16,123(45.6)$ & \\
\hline$>65$ & $7513(17.0)$ & $1503(17.1)$ & $6010(17.0)$ & \\
\hline Male & $22,610(51.2)$ & $4643(52.8)$ & $17,967(50.8)$ & 0.001 \\
\hline \multicolumn{5}{|l|}{ Marital status } \\
\hline Unmarried & $5497(12.5)$ & $2687(30.6)$ & $2810(8.0)$ & \multirow[t]{5}{*}{$<0.001$} \\
\hline Married & $34,955(79.2)$ & $5265(59.9)$ & $29,690(84.0)$ & \\
\hline Widowed & $3198(7.2)$ & $733(8.3)$ & $2465(7.0)$ & \\
\hline Divorced & $436(1.0)$ & $83(0.9)$ & $353(1.0)$ & \\
\hline Others & $48(0.1)$ & $21(0.2)$ & $27(0.1)$ & \\
\hline Senior high school and below & $34,605(78.4)$ & $5942(67.6)$ & $28,663(81.1)$ & $<0.001$ \\
\hline In agriculture industry & $36,825(83.4)$ & $7074(80.5)$ & $29,751(84.2)$ & $<0.001$ \\
\hline \multicolumn{5}{|l|}{ Employment status } \\
\hline Employed & $32,545(73.7)$ & $5246(59.7)$ & $27,299(77.2)$ & \multirow[t]{4}{*}{$<0.001$} \\
\hline Retiree & $2756(6.2)$ & $478(5.4)$ & $2278(6.4)$ & \\
\hline Student & $1999(4.5)$ & $1256(14.3)$ & $743(2.1)$ & \\
\hline Unemployed & $6834(15.5)$ & 1809 (20.6) & $5025(14.2)$ & \\
\hline \multicolumn{5}{|l|}{ Smoking status } \\
\hline Smoker & $13,742(31.1)$ & $2412(27.4)$ & $11,330(32.1)$ & \multirow[t]{3}{*}{$<0.001$} \\
\hline Ex-smoker & $1316(3.0)$ & $202(2.3)$ & $1114(3.2)$ & \\
\hline Non-smoker & 29,076 (65.9) & $6175(70.3)$ & 22,901 (64.8) & \\
\hline \multicolumn{5}{|l|}{ Alcohol consumption } \\
\hline 1-2 times a week & $6563(14.9)$ & $1203(13.7)$ & $5360(15.2)$ & \multirow[t]{3}{*}{$<0.001$} \\
\hline$\geq 3$ times a week & $1763(4.0)$ & $287(3.3)$ & $1476(4.2)$ & \\
\hline Non-drinker & $35,808(81.1)$ & 7299 (83.0) & $28,509(80.7)$ & \\
\hline \multicolumn{5}{|l|}{ Physical exercise } \\
\hline$\geq 6$ times a week & 4785 (10.8) & $1004(11.4)$ & $3781(10.7)$ & \multirow[t]{3}{*}{$<0.001$} \\
\hline$<6$ times a week & $5636(12.8)$ & $1383(15.7)$ & $4253(12.0)$ & \\
\hline Never exercised & $33,713(76.4)$ & $6402(72.8)$ & $27,311(77.3)$ & \\
\hline Chronic disease morbidity & $10,152(23.0)$ & $1572(17.9)$ & $8580(24.3)$ & $<0.001$ \\
\hline Two-week morbidity rate & 8621 (19.5) & $1323(15.1)$ & 7298 (20.6) & $<0.001$ \\
\hline Hospitalized & $4191(9.5)$ & $682(7.8)$ & 3509 (9.9) & $<0.001$ \\
\hline
\end{tabular}

sample. Subject to the sampling design reported in our previous study [43], a total of 32 counties (districts), 160 townships (streets), 320 rural or residential committees, 20,700 households and 57,529 people were selected. The survey questionnaire included more than 200 questions relating to the area of socio-economic characteristics, health status, health risks and health service needs and utilization. Household interviews were used to collect the data. It allows family members familiar with the recent situation of the intended respondents to take the interview, as proxies. Rigorous quality control measures were taken at every stage to ensure the quality of the survey, and the good quality was also evidenced by its Myer's blended index, which is a method to evaluate the quality of the survey. The Myer's blended index shows a range of $0-99$. Zero denotes a consistency in age distribution of the sample and of the population, and 99 denotes that the age of the samples ends with the same number. The Myer's blended index greater than 60 indicates that the investigated sample has a serious age preference. The Myer's 


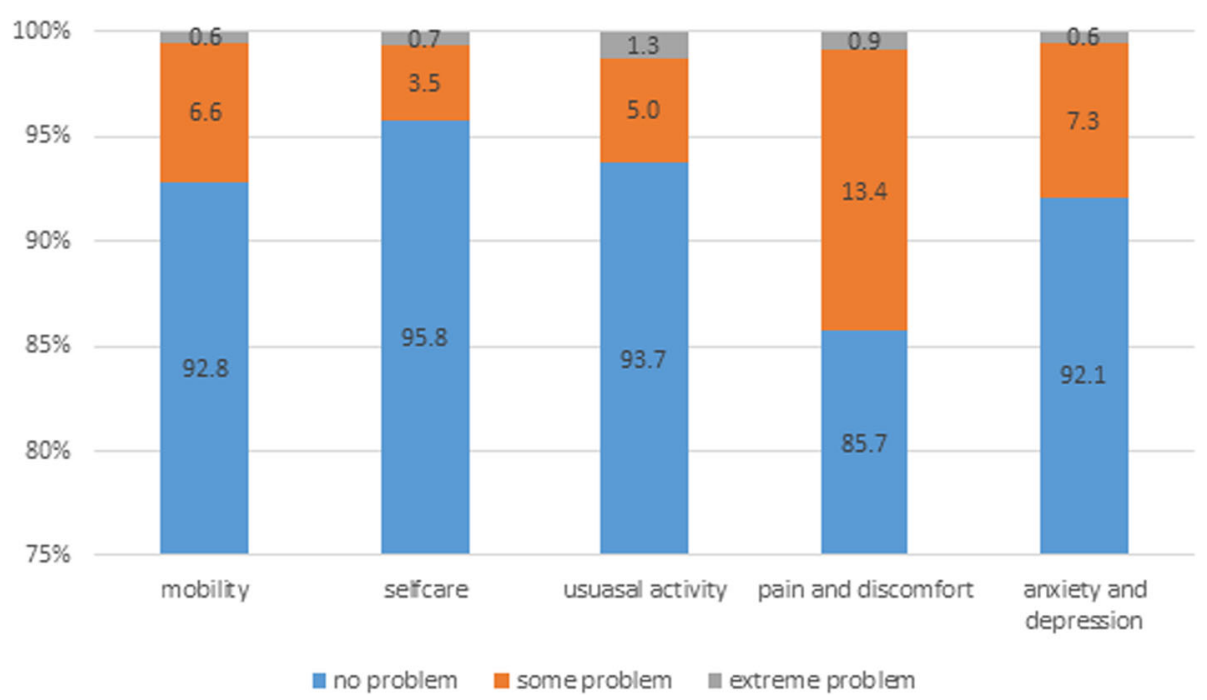

Fig. 1 Results of EQ-5D-3 L in the overall population

blended index of the sample in this study was only 1.3. Participants aged 15 and above were included and all individuals with missing values among EQ-5D-3 L and other analysis variables were excluded. Finally, a total of 44,134 individuals were chose in the analysis.

\section{EQ-5D-3 L instrument}

EQ-5D-3 L has gained widespread popularity for it is easy to be administered, scored, and interpreted, especially in large-scale face-to-face health interview surveys. EQ-5D-3 L has been included in NHSS since 2008. EQ-5D-3 L consists of two components, the EQ-5D-3 L health descriptive system and EQ VAS. The former, EQ-5D-3 L health descriptive system, is comprised of 5 dimensions, including mobility (MO), self-care (SC), usual activities (AC), pain/discomfort (PD), and anxiety/depression (AD). Each dimension consists of three categories, namely, no problems, some problems, and extreme problems. In general population, the proportion of reporting extreme problems (the third level) in each dimension of EQ-5D-3 L is very low [42]. To simplify the expression of the proportion of reporting health problems and to improve the robustness of the estimations of the proxy response bias, the original response outcome in each dimension was transformed into two categories (reporting no problem and reporting any problem). Chinese time trade-off values were used to calculate the EQ-5D-3 $\mathrm{L}$ index based on these five dimensions [44]. The EQ VAS is a $20-\mathrm{cm}$ long vertical visual scale, with the highest score of 100 corresponding to "the best health you can imagine", while the bottom score of 0 corresponding to "the worst health status you can imagine".

\section{Other important variables}

The following question was used to identify proxy responses:

"Q31. Who answers the following questions (judged by the investigator)?

i. Answer by yourself

ii. Reply by others

Thirteen covariates were used to calculate propensity score, including socio-demographic factors, health behavior, and health status associated factors. Continuous covariates and categorical covariates with too many levels were reclassified, such as age (15-44, 45-64, and 65+ years, which representing the young adult, the middleaged, and the aged population respectively), physical exercise (never exercised, less than 6 times a week, and more than 6 times a week), and educational level (above senior high school and senior high school and below).

\section{Statistical analysis \\ Description of the sample characteristics and EQ-5D reporting results}

The participants were divided into self-report and proxy-report groups before PSM. Chi-squared tests were employed to compare group differences among sociodemographic factors, health behavior, and the dimensional results of EQ-5D-3 L. The relationships between the characteristics and the likelihood of proxy response were examined via Chi-squared test (categorical variables) and one-way ANOVA (continuous variables) to 
Table 2 Comparison of baseline characteristics after PSM

\begin{tabular}{|c|c|c|c|}
\hline & $\begin{array}{l}\text { Proxy-report } \\
(n=8190)\end{array}$ & $\begin{array}{l}\text { Self-report } \\
(n=14,092)\end{array}$ & $P$-value \\
\hline Household heads & $1698(20.7)$ & $3529(25.0)$ & $<0.001$ \\
\hline \multicolumn{4}{|l|}{ Age (y) } \\
\hline $15-44$ & $4480(54.7)$ & 7107 (50.4) & \multirow[t]{3}{*}{$<0.001$} \\
\hline $45-64$ & $2213(27.0)$ & $4267(30.3)$ & \\
\hline$>65$ & $1497(18.3)$ & $2718(19.3)$ & \\
\hline Male & $4284(52.3)$ & $7172(50.9)$ & 0.042 \\
\hline \multicolumn{4}{|l|}{ Marital status } \\
\hline Unmarried & $2104(25.7)$ & $2457(17.4)$ & \multirow[t]{5}{*}{$<0.001$} \\
\hline Married & $5264(64.3)$ & $10,270(72.9)$ & \\
\hline Widowed & $727(8.9)$ & $1208(8.6)$ & \\
\hline Divorced & $83(1.0)$ & $142(1.0)$ & \\
\hline Others & $12(0.1)$ & $15(0.1)$ & \\
\hline Senior high school and below & 5857 (71.5) & 10,394 (73.8) & $<0.001$ \\
\hline In agriculture industry & $6546(79.9)$ & $11,248(79.8)$ & 0.846 \\
\hline \multicolumn{4}{|l|}{ Employment status } \\
\hline Employed & 5208 (63.6) & $9426(66.9)$ & \multirow[t]{4}{*}{$<0.001$} \\
\hline Retiree & $478(5.8)$ & $970(6.9)$ & \\
\hline Student & 729 (8.9) & $736(5.2)$ & \\
\hline Unemployed & $1775(21.7)$ & $2960(21.0)$ & \\
\hline \multicolumn{4}{|l|}{ Smoking status } \\
\hline Smoker & $2385(29.1)$ & $4265(30.3)$ & \multirow[t]{3}{*}{0.002} \\
\hline Ex-smoker & $199(2.4)$ & $432(3.1)$ & \\
\hline Non-smoker & $5606(68.4)$ & $9395(66.7)$ & \\
\hline \multicolumn{4}{|l|}{ Alcohol consumption } \\
\hline $1-2$ times a week & $1174(14.3)$ & $2157(15.3)$ & \multirow[t]{3}{*}{0.134} \\
\hline$\geq 3$ times a week & $287(3.5)$ & $503(3.6)$ & \\
\hline Non-drinker & $6729(82.2)$ & $11,432(81.1)$ & \\
\hline \multicolumn{4}{|l|}{ Physical exercise } \\
\hline$\geq 6$ times a week & $859(10.5)$ & $1518(10.8)$ & \multirow[t]{3}{*}{0.009} \\
\hline$<6$ times a week & $1247(15.2)$ & $1936(13.7)$ & \\
\hline Never exercised & $6084(74.3)$ & $10,638(75.5)$ & \\
\hline Chronic disease morbidity & $1560(19.0)$ & $2931(20.8)$ & 0.002 \\
\hline Two-week morbidity & 1304 (15.9) & 2349 (16.7) & 0.146 \\
\hline Hospitalized & $674(8.2)$ & $1196(8.5)$ & 0.504 \\
\hline
\end{tabular}

establish whether proxy was more likely to be used in some groups compared with others. A percent bar chart was adopted to summarize the original response results of 5 dimensions of EQ-5D-3 L for the overall population.

\section{Implementation of PSM and balance checking}

We speculated that the EQ-5D-3 L results of proxyreport and self-report respondents should be consistent when the two groups of respondents share the similar characteristics. Then, PSM was used to adjust their distribution of the main characteristics to the same level. After PSM, the difference of EQ-5D-3 L results between the two groups was regarded as proxy response bias. In PSM, proxy-report respondents were matched to selfreport respondents with similar characteristics using a propensity score (PS), which was defined as the conditional probability of the individual being assigned to the proxy-report group. Multivariate logistic regression model was used to calculate PS. In the model, the dependent variable was the log of proxy and the independent variables were a set of conditioning variables, including socio-demographic factors, health behavior, and health status.

Nearest neighbor matching, which is one of the most widely used PSM methods, was chose in this study. The matching ratio was set to $1: 2$ for the following two reasons. First, before PSM, a total of 35,345 (80.1\%) and 8789 (19.9\%) respondents were restricted to self-report and proxy-report groups respectively. Then, we tried three matching ratios (1:2, 1:3 and 1:4) and the results showed that the number of unmatched cases in the treatment group was the least and the matching rate was the highest by 1:2 matching (see supplementary material for the matching results of 1:2, 1:3 and 1:4 matching). Second, Guo stated that 1:n matching was more efficient than 1:1 matching; however, when $n$ was too large, it was impossible to allocate enough matched control group members for each treatment group member and the benefits of a large number of control group members were negligible [45]. The caliper width was set to 0.03 for the following two reasons. First, Austin PC recommended researchers to match on the logit of the propensity score using calipers of width equal to 0.2 of the standard deviation of the logit of the propensity score [46]. Second, the standard deviation of the logit of the propensity score in this study was 0.152369 , and 0.2 times this value was approximately 0.03 .

Standardized difference was used to check the balance of confounding factors after PSM. The balance of a confounder achieved once its standardized difference was lower than 10\% after PSM [47]. PSM assumes that there remains no unobserved confounding. In this study, we use Harding's approaches to test the underlying assumption of PSM that there remains no unobserved confounders [48] (see supplementary material for details about the method).

\section{Analysis of proxy response effects}

Proxy response effects were evaluated by using logistic regression model (conditional logistic model after PSM) and general linear model respectively to calculate the odds ratio (for EQ-5D-3 L dimensions) and mean differences (for EQ-5D-3 L index and EQ VAS), both with a $95 \%$ confidence interval (CI). In 


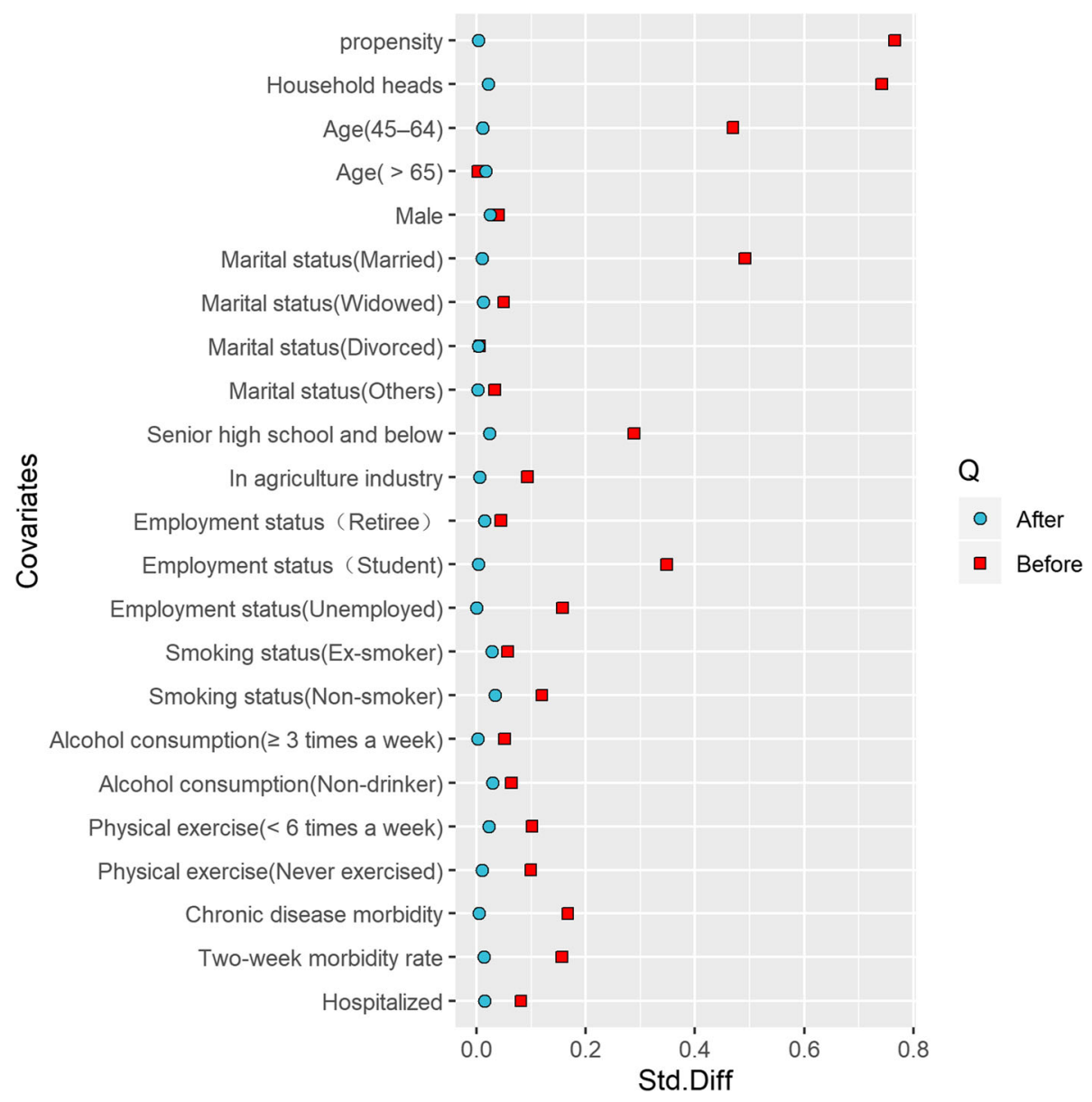

Fig. 2 Absolute standardized differences before and after PSM

the logistic models, each of the 5 transformed EQ5D-3 L dimensions was the dependent variable and the proxy indicator was the independent variable. In the general linear models, EQ-5D index or EQ VAS was used as the dependent variable while proxy indicator remained as the independent variable.

PSM was performed using the SPSS plug-in psmatching 3.02. Before and after PSM, all the statistical analysis was performed using SPSS 24.0. A difference of $P<0.05$ was considered to be statistically significant.

\section{Results}

Overall, 8789 (19.9\%) intended respondents were reported by proxies. Table 1 presents the general characteristics of the sample and the difference between selfreport and proxy-report groups before PSM. The group differences of the 13 covariates considered in Table 1 were all statistically significant $(\mathrm{P}<0.05)$. In terms of the socio-demographic factors, the proxy-report group, compared with self-report group, showed a lower proportion of household heads, younger age, a higher

Table 3 Risk of proxy-report group to report any problems compared with self-report group before and after PSM

\begin{tabular}{|c|c|c|c|c|c|c|c|c|}
\hline \multirow[t]{2}{*}{ EQ-5D } & \multicolumn{4}{|l|}{ Before PSM } & \multicolumn{4}{|l|}{ After PSM } \\
\hline & Proxy-report & Self-report & $\mathrm{OR}(95 \% \mathrm{Cl})^{\mathrm{a}}$ & $P$ value & Proxy-report & Self-report & $\mathrm{OR}(95 \% \mathrm{Cl})^{\mathrm{a}}$ & $P$-value \\
\hline Mobility & $828(9.4)$ & $2351(6.7)$ & $1.46(1.34-1.59)$ & $<0.001$ & $820(10.0)$ & $960(6.8)$ & $1.52(1.38-1.68)$ & $<0.001$ \\
\hline Self-care & $629(7.2)$ & $1224(3.5)$ & $2.15(1.95-2.37)$ & $<0.001$ & $623(7.6)$ & $524(3.7)$ & $2.13(1.892-2.40)$ & $<0.001$ \\
\hline Usual activity & 841 (9.6) & $1958(5.5)$ & $1.80(1.66-1.96)$ & $<0.001$ & $833(10.2)$ & $837(5.9)$ & $1.79(1.622-1.98)$ & $<0.001$ \\
\hline Pain/discomfort & $1166(13.3)$ & $5144(14.6)$ & $0.90(0.84-0.96)$ & 0.002 & $1157(14.1)$ & 1815 (12.9) & $1.11(1.028-1.21)$ & 0.008 \\
\hline Anxiety/depression & $765(8.7)$ & $2719(7.7)$ & $1.14(1.05-1.24)$ & 0.002 & $755(9.2)$ & $986(7.0)$ & $1.35(1.223-1.49)$ & $<0.001$ \\
\hline
\end{tabular}

${ }^{a}$ Self-reported group was the reference 
Table 4 Means of EQ-5D index and VAS and the differences between proxy-report and self-report groups before and after PSM

\begin{tabular}{|c|c|c|c|c|c|c|c|c|}
\hline \multirow[t]{2}{*}{ Indicators } & \multicolumn{4}{|l|}{ Before PSM } & \multicolumn{4}{|l|}{ After PSM } \\
\hline & Proxy-report & Self-report & Difference $(95 \% \mathrm{Cl})$ & $P$ & Proxy-report & Self-report & Difference $(95 \% \mathrm{Cl})$ & P \\
\hline EQ - 5D index ${ }^{a}$ & $0.929(0.178)$ & $0.943(0.132)$ & $-0.014(-0.018,-0.011)$ & $<0.001$ & $0.946(0.134)$ & $0.924(0.183)$ & $-0.022(-0.026,-0.018)$ & $<0.001$ \\
\hline EQ - VAS & $81.16(15.37)$ & $80.43(12.88)$ & $0.73(0.417,1.043)$ & $<0.001$ & $81.40(13.20)$ & $80.50(15.50)$ & $-0.83(-1.218,-0.450)$ & $<0.001$ \\
\hline
\end{tabular}

${ }^{\text {a }}$ The range of EQ-5D is $0-1$. In order to express the small difference of EQ-5D index, three decimal numbers is retained

proportion of unmarried and students, and a higher educational level. As for health behavior, the lifestyle of proxy-report group was much healthier with lower proportions of smoking and drinking and higher frequency of exercising. In addition, the health condition of proxyreport group was much better with lower proportions of participants who suffered from chronic diseases, were sick within two-week, and were hospitalized within 1 year.

In the overall population, the means of EQ-5D-3 L index and EQ VAS were 0.94 and 80.58 respectively. The original dimensional results are presented in Fig. 1. In general, the respondents reported health problems most in pain/discomfort dimension (14.3\%) and least in self-care (4.2\%). The proportion of reporting some problems in the pain/discomfort dimension was highest (13.4\%), followed by anxiety/depression (7.3\%), mobility (6.6\%), usual activities (5.0\%), and self-care (3.5\%). The dimension reporting the most extreme problems was usual activities $(1.3 \%)$, followed by self-care $(0.9 \%)$.

A total of 22,282 people were matched after PSM, of which 8190 were in the proxy-report group and 14,092 were in the self-report group. The between-group differences of all the covariates decreased and some of which, such as occupation (in agriculture industry), alcohol consumption, two-week morbidity, and hospitalization (Table 2),were statistically non-significant with $P$ values of Chi-squared tests larger than 0.05 . Figure 2 shows that the standardized differences of all the 13 covariates are smaller than $10 \%$, which indicates that PSM has really improved the between-group balance of the covariates.

Tables 3 and 4 present the response results of EQ-5D for dimensions and scores respectively before and after PSM. Before PSM, proxy-report group was more likely to rate health problems in $\mathrm{MO}, \mathrm{SC}$, $\mathrm{UA}$, and $\mathrm{AD}$, except for PD (Table 3). The EQ-5D-3 L index of proxy-report group was 0.014 lower than that of self-report group, whilst the EQ VAS of the proxy-report group was 0.73 higher than that of the self-report group (Table 4). After PSM, the proportions of reporting any problems in the 5 dimensions were all significantly higher in the proxy-report group (Table 3). Compared with self-report group, all the odds ratios in the 5 dimensions were significantly larger than one, among which the largest dimension was SC, then followed by UA, MO, AD, and PD (Table 3). Simultaneously, proxy-report group got significantly lower means of EQ-5D-3 L index and EQ VAS (Table 4). These figures indicated that, after adjusting the measured confounding factors, consistent proxy response bias of EQ5D-3 L among different constructs was identified, and the proxies were likely to underestimate the health status of the intended respondents, even though the magnitude of the proxy response bias varied greatly among different dimensions of EQ-5D-3 L and the difference of EQ-5D-3 L index and EQ VAS were relative low.

In the Harding's approach, we supposed that there was unobserved binary confounder and specified the range of prevalence of the unobserved confounder among the self-reported group from 1 to $25 \%$. The test results showed that the OR values of the five dimensions were very similar with those before being adjusted for unobserved confounding, indicating that the likelihood of reporting any health problems on each dimension was not sensitive to an unobserved confounder (see supplementary material for details about the method and results of sensitive analysis for unobserved confounding). Based on this evidence, we believe that it is reasonable to assume that there were no important confounders that remained uncontrolled for and thus the PSM was an appropriate method in this study.

\section{Discussion}

Many studies have shown that the application of proxy response in the evaluation of objective and subjective health indicators would lead to selection bias [29]. This study try to evaluate the proxy response bias of Chinese EQ-5D-3 L in general population by using PSM and confirms that proxies are likely to report more health problems in EQ-5D-3 L and therefore leads to negative proxy response bias, which is consistent with most existing research findings. However, some of the results are inconsistent with those of previous studies.

First, the intended respondents of proxy-report group in this study were quite different from those in previous studies. In the existing studies, the intended respondents of proxy-report groups were mostly elderly people with diseases (such as disability, dementia, cognitive impairment, etc.) $[16,18,21,23-26,28]$, while the proxyreport group in this study were younger and with lower prevalence of smoking, drinking, chronic disease, twoweek morbidity and half-year hospitalization. The interviews were mainly conducted on weekdays, a time when most young and middle-aged migrant workers and 
students were not at home, especially in rural area, which may contribute to this age distribution difference.

Second, the magnitude of the proxy response bias among different dimensions of EQ-5D-3 L is inconsistent with most previous studies. After applying PSM, the proxy response bias sequence of the five dimensions was as follows: self-care, usual activity, mobility, anxiety/depression, and pain/discomfort. It suggested that the proxy response bias in physical dimensions (self-care, usual activity, mobility) was larger than those in psychological dimensions (anxiety/depression, pain/discomfort.), which was, however, contrary to the conclusions of existing studies [17, 20,22]. These studies used kappa values to evaluate the agreement between self-report and proxy-report groups, and found that they showed more agreement on mobility, self-care, and usual activities than on pain/discomfort and anxiety/depression, which suggested that the proxy response bias of physical dimensions was smaller than that of psychological dimensions. Studies have also shown that the proxy response bias is most significant in psychological aspects and proxy responses are not suitable for the anxiety dimension $[49,50]$. Similar to our findings, a study done in UK on residents aged $>85$ years also reported highest proxy response bias in the self-care dimension [51].

The negative proxy response bias may be explained by the following reasons. First, if the proxies are in a poor the physical health status $[50,52,53]$, it may be projected onto the HRQL evaluation of the intended respondents. Second, the proxy and the intended respondents may not in a fairly close relation. When spouses were proxies, as some studies suggested, the proxy response bias produced was less than that made by other types of proxies $[49,54,55]$. Third, the proxies may face great caregiver stress if he/she was a caregiver of the intended respondents [53, 56]. There are also some possible reasons for the characteristics of the magnitude of the proxy response bias among different dimensions. The self-care ability of intended respondents would directly affect the care burden of other family members. Therefore, other family members may overestimate the care services provided by them and report relatively poorer HRQL. However, the overestimation of health problems in the anxiety/depression and pain/discomfort dimensions by proxies is relatively low because the condition of intended respondents in these dimensions may not have a great effect on the care difficulty for the caregivers.

In this study, the EQ-5D-3 L index and EQ VAS were very high because the subjects of this study were selected from general population, who were more prone to report very low proportion of health problems. Therefore, the difference of the absolute values of EQ-5D-3 L index and EQ VAS between proxy-report and self-report groups was -0.022 and -0.834 respectively. It was very low and seemed to be meaningless. However, the proxyreported group was 52, 113, 79, 11 and 35\% more likely to report health problems on the five dimensions respectively, indicating very large relative difference. In addition, the proxy response rate of NHSS is as high as $19.9 \%$. Thus, it is necessary to adjust proxy response bias of EQ-5D-3 L in studies based on NHSS data. This study is the first time to analyze the proxy response effect of Chinese version of EQ-5D-3 L based on NHSS data, which is of great significance for the evaluation of proxy response bias in Chinese EQ-5D-3 L and provide valuable knowledge for the application of Chinese EQ-5D-3 $\mathrm{L}$ in HTA in the future.

\section{Study limitations}

This study had several limitations. First, the study use proxies mostly for the reason that the intended respondents are not at home, rather than unable to report, which suggests that the proxies are in most cases family members, not necessarily caregivers. Therefore, it is difficult to verify the proxies' familiarity with the health status of the intended respondents, and the rationality and validity of the using of proxies need to be further studied. Second, the information about the role of the proxy was not collected, therefore the effect of the proxy type could not be analyzed. Third, the EQ-5D-3 L results of the matched pairs are not from the exactly same respondent. Future studies with paired design in which both the proxies and the intended respondents report the proxy version of EQ-5D-3 $\mathrm{L}$ are needed to determine the "real" proxy bias in general population.

\section{Conclusions}

Significant negative proxy response bias was found in Chinese version of EQ-5D-3 L in general population, and the magnitude of the bias was larger in physical dimensions than psychological dimensions by using PSM to control confounders. It provided valuable knowledge for the application of Chinese EQ-5D-3 L in HTA in the future.

\section{Supplementary information}

Supplementary information accompanies this paper at https://doi.org/10. 1186/s12955-020-01325-z.

Additional file 1. Method and results of sensitive analysis for unobserved confounding.

\section{Abbreviations}

AC: Usual activities; AD: Anxiety/depression; BRFSS: Behavioral risk factor surveillance system; Cl: Confidence interval; HRQL: Health-related quality of life; MO: Mobility; NHIS: National Health Interview Survey; NHSS: National Health Service Survey; OR: Odds ratio; PD: Pain/discomfort; PSM: Propensity score matching; RCT: Randomized controlled trials; SC: Self-care; VAS: Visual analogue scale 


\section{Acknowledgments}

We appreciate the support from the officers of the surveyed counties and the assistance in the coordination of this study, the interviewers for their excellent field work, and all respondents for their cooperation. We also thank Qingyi Wang for her help in the English language revision.

\section{Authors' contributions}

Ying Liang, Yongyong $\mathrm{Xu}$, Zhijun Tan were involved in the conception or the design of the study. Ying Liang, Tianle Che, Haiyue Zhang, Lingxia Guo and Zhijun Tan participated in the collection or generation of the study data. Ying Liang, Tianle Che, Haiyue Zhang and Zhijun Tan were involved in the analysis or interpretation of the data. All authors participated in the development of this manuscript. The authors read and approved the final manuscript.

\section{Funding}

This work has been founded by National Natural Science Foundations (No. 81703315, No. 81773540, No. 81573250, No.81573252) and Key R \& D plan of Shaanxi Province (No.2019SF-143). The funder did not play any role in the study.

\section{Availability of data and materials}

Not applicable.

\section{Ethics approval and consent to participate}

The NHSS obtained ethics approval (license number: 2013 (65)) from the institutional review board of the Chinese National Bureau of Statistics. The NHSS is implemented by the $\mathrm{MOH}$ every 5 years and the $\mathrm{MOH}$ has pledged to protect the privacy of respondents and to facilitate the anonymous analysis of the data according to article 14 of the third chapter of the Statistics Law of the People's Republic of China. For these reasons, a written consent was not required. The investigators read the informed consent statement on the second page of the questionnaire and verbally asked for the interviewees' permission. Once the interviewees or their caregivers or guardians (in the case of children) had verbally consented to participate in this study, the investigators would sign their own names at the beginning of the questionnaire.

\section{Consent for publication}

Not applicable.

\section{Competing interests}

The authors declare that they have no competing interests.

\section{Author details}

'Department of Health Statistics, Fourth Military Medical University, Xi'an, Shaanxi Province, China. ${ }^{2}$ Ministry of Education Key Lab of Hazard Assessment and Control in Special Operational Environment, Fourth Military Medical University, Xi'an, Shaanxi Province, China. ${ }^{3}$ Center of Health Statistics, Health General Office of Shaanxi Province, Xi'an, Shaanxi Province, China.

\section{Received: 18 September 2019 Accepted: 11 March 2020}

\section{Published online: 18 March 2020}

\section{References}

1. Department of Health and Human Services (US). Healthy people 2000 Washington: DHHS, Office of the Surgeon General (US); 1992.

2. Department of Health and Human Services (US). Healthy people 2010 Washington: DHHS, Office of the Surgeon General (US); 2000.

3. Patrick DL, Erickson P. Health status and health policy: quality of life in health care evaluation and resource allocation. New York: Oxford University Press; 1993.

4. Pappa E, Kontodimopoulos N, Papadopoulos AA, Niakas D. Assessing the socio-economic and demographic impact on health-related quality of life: evidence from Greece. Int J Public Health. 2009;54(4):241-9.

5. Li M, Harris I, Lu ZK. Differences in proxy-reported and patient-reported outcomes: assessing health and functional status among medicare beneficiaries. BMC Med Res Methodol. 2015;15:62.

6. Roydhouse JK, Gutman R, Keating NL, Mor V, Wilson IB. Proxy and patient reports of health-related quality of life in a national cancer survey. Health Qual Life Outcomes. 2018;16(1):6.

7. Ellis $\mathrm{BH}$, Bannister WM, Cox JK, et al. Utilization of the propensity score method: an exploratory comparison of proxy-completed to self-completed responses in the Medicare health outcomes survey. Health Qual Life Outcomes. 2003:1:47.

8. Roydhouse JK, Wilson IB. Systematic review of caregiver responses for patient health-related quality of life in adult cancer care. Qual Life Res. 2017; 26(8):1925-54

9. von Essen L. Proxy ratings of patient quality of life--factors related to patient-proxy agreement. Acta Oncol. 2004;43(3):229-34.

10. Rabin R, de Charro F. EQ-5D: a measure of health status from the EuroQol group. Ann Med. 2001;33(5):337-43.

11. Devlin NJ, Brooks R. EQ-5D and the EuroQol group: past, present and future. Appl Health Econ Health Policy. 2017;15(2):127-37.

12. Lloyd A, Pickard AS. The EQ-5D and the EuroQol group. Value Health. 2019; 22(1):21-2.

13. Rencz F, Gulácsi L, Drummond M, Dominik G, Valentina PR, Judit S, et al. EQ-5D in central and Eastern Europe: 2000-2015. Qual Life Res. 2016:25(11):2693-710.

14. Rowen D, Azzabi ZI, Chevrou-Severac H, van Hout B, et al. International regulations and recommendations for utility data for health technology assessment. PharmacoEconomics. 2017;35:11-9.

15. Guoen Liu. 2015 China guidelines for Pharmacoeconomic evaluation and manual. Beijing: Science Press. 2015. (In Chinese).

16. Coucill W, Bryan S, Bentham P, Buckley A, Laight A. EQ-5D in patients with dementia: an investigation of inter-rater agreement. Med Care. 2001;39(8):760-71.

17. Pickard AS, Johnson JA, Feeny DH, Shuaib A, Carriere KC, Nasser AM. Agreement between patient and proxy assessments of health-related quality of life after stroke using the EQ-5D and health utilities index. Stroke. 2004;35(2):607-12.

18. Bryan S, Hardyman W, Bentham P, Buckley A, Laight A. Proxy completion of EQ-5D in patients with dementia. Qual Life Res. 2005;14(1):107-18.

19. Sach $T H$, Barton GR. Interpreting parental proxy reports of (health-related) quality of life for children with unilateral cochlear implants. Int J Pediatr Otorhinolaryngol. 2007;71(3):435-45.

20. Hung MC, Yan YH, Fan PS, et al. Measurement of quality of life using EQ-5D in patients on prolonged mechanical ventilation: comparison of patients, family caregivers, and nurses. Qual Life Res. 2010;19(5):721-7.

21. Hounsome N, Orrell M, Edwards RT. EQ-5D as a quality of life measure in people with dementia and their carers: evidence and key issues. Value Health. 2011;14(2):390-9.

22. Dinglas VD, Gifford JM, Husain N, Colantuoni E, Needham DM. Quality of life before intensive care using EQ-5D: patient versus proxy responses. Crit Care Med. 2013:41(1):9-14.

23. Arons AM, Krabbe PF, Scholzel-Dorenbos CJ, van der Wilt GJ, Rikkert MG. Quality of life in dementia: a study on proxy bias. BMC Med Res Methodol. 2013:13:110.

24. Diaz-Redondo A, Rodriguez-Blazquez C, Ayala A, Martinez-Martin P, Forjaz MJ. EQ-5D rated by proxy in institutionalized older adults with dementia: psychometric pros and cons. Geriatr Gerontol Int. 2014;14(2):346-53.

25. Orgeta V, Edwards RT, Hounsome B, Orrell M, Woods B. The use of the EQ$5 \mathrm{D}$ as a measure of health-related quality of life in people with dementia and their carers. Qual Life Res. 2015;24(2):315-24.

26. Davis JC, Hsiung GY, Bryan S, et al. Agreement between patient and proxy assessments of quality of life among older adults with vascular cognitive impairment using the EQ-5D-3L and ICECAP-O. PLOS One. 2016:11(4):e0153878.

27. Bray N, Noyes J, Harris N, Edwards RT. Measuring the health-related quality of life of children with impaired mobility: examining correlation and agreement between children and parent proxies. BMC Res Notes. 2017;10(1):377.

28. Usman A, Lewis S, Hinsliff-Smith $\mathrm{K}$, et al. Measuring health-related quality of life of care home residents: comparison of self-report with staff proxy responses. Age Ageing. 2019:48(3):407-13.

29. Graham C. Incidence and impact of proxy response in measuring patient experience: secondary analysis of a large postal survey using propensity score matching. International J Qual Health Care. 2016;28(2):246-52.

30. Edwards VJ, Anderson LA, Deokar AJ. Proxy reports about household members with increased confusion or memory loss, 2011 behavioral risk factor surveillance system. Prev Chronic Dis. 2015;12:E47.

31. Wolinsky FD, Jones MP, Wehby GL. Gathering data from older adults via proxy respondents: research challenges. J Comp Eff Res. 2012;1(6):467-70.

32. Todorov A, Kirchner C. Bias in proxies' reports of disability: data from the National Health Interview Survey on disability. Am J Public Health. 2000; 90(8):1248-53.

33. Kim K, Kim JS. The association between alcohol consumption patterns and health-related quality of life in a nationally representative sample of south Korean adults. PLoS One. 2015;10(3):e0119245. 
34. Huber MB, Reitmeir P, Vogelmann M, Leidl R. EQ-5D-5L in the general German population: comparison and evaluation of three yearly crosssection surveys. Int J Environ Res Public Health. 2016;13(3):343.

35. McCaffrey N, Kaambwa B, Currow DC, Ratcliffe J. Health-related quality of life measured using the EQ-5D-5L: south Australian population norms. Health Qual Life Outcomes. 2016;14(1):133.

36. Kind P, Dolan P, Gudex C, Williams A. Variations in population health status: results from a United Kingdom national questionnaire survey. BMJ. 1998; 316(7133):736-41.

37. Garcia-Gordillo MA, Adsuar JC, Olivares PR. Normative values of EQ-5D-5L: in a Spanish representative population sample from Spanish health survey, 2011. Qual Life Res. 2016;25(5):1313-21.

38. Huber MB, Felix J, Vogelmann M, Leidl R. Health-related quality of life of the general German population in 2015: results from the EQ-5D-5L. Int J Environ Res Public Health. 2017:14(4):426.

39. Rosenbaum PR, Rubin DB. The central role of the propensity score in observational studies for causal effects. Biometrika. 1983;70:41-55.

40. Rubin DB. The design versus the analysis of observational studies for causal effects: parallels with the design of randomized trials. Stat Med. 2007;26(1):20-36.

41. Sun S, Chen J, Johannesson M, et al. Population health status in China: EQ$5 \mathrm{D}$ results, by age, sex and socio-economic status, from the National Health Services Survey 2008. Qual Life Res. 2011;20(3):309-20.

42. Tan Z, Liang Y, Liu S, et al. Health-related quality of life as measured with EQ-5D among populations with and without specific chronic conditions: a populationbased survey in Shaanxi Province, China. PLoS One. 2013;8(7):e65958.

43. Tan Z, Shi F, Zhang H, Li N, Xu Y, Liang Y. Household income, income inequality, and health-related quality of life measured by the EQ-5D in Shaanxi, China: a cross-sectional study. Int J Equity Health. 2018;17(1):32.

44. Liu GG, Wu H, Li M, Gao C, Luo N. Chinese time trade-off values for EQ-5D health states. Value Health. 2014;17(5):597-604.

45. Guo SY, Fraser MW. Propensity score analysis: statistical methods and applications. SAGE Publications; 2014.

46. Austin PC. Optimal caliper widths for propensity-score matching when estimating differences in means and differences in proportions in observational studies. Pharm Stat. 2011:10(2):150-61.

47. Austin PC. Balance diagnostics for comparing the distribution of baseline covariates between treatment groups in propensity-score matched samples. Stat Med. 2009;28(25):3083-107.

48. Liu W, Kuramoto SJ, Stuart E. An introduction to sensitivity analysis for unobserved confounding in non-experimental prevention research. Prev Sci. 2013;14(6):570-80

49. Pickard AS, Lin HW, Knight SJ, et al. Proxy assessment of health-related quality of life in african american and white respondents with prostate cancer: perspective matters. Med Care. 2009;47(2):176-83.

50. Sneeuw KC, Aaronson NK, Sprangers MA, Detmar SB, Wever LD, Schornagel $\mathrm{JH}$. Comparison of patient and proxy EORTC QLQ-C30 ratings in assessing the quality of life of cancer patients. J Clin Epidemiol. 1998;51(7):617-31.

51. Devine A, Taylor SJ, Spencer A, Diaz-Ordaz K, Eldridge S, Underwood M. The agreement between proxy and self-completed EQ-5D for care home residents was better for index scores than individual domains. J Clin Epidemiol. 2014;67(9):1035-43.

52. Hung SY, Pickard AS, Witt WP, Lambert BL. Pain and depression in caregivers affected their perception of pain in stroke patients. J Clin Epidemiol. 2007;60(9):963-70.

53. Tang ST. Predictors of the extent of agreement for quality of life assessments between terminally ill cancer patients and their primary family caregivers in Taiwan. Qual Life Res. 2006;15(3):391-404.

54. Sandgren AK, Mullens AB, Erickson SC, Romanek KM, McCaul KD. Confidant and breast cancer patient reports of quality of life. Qual Life Res. 2004;13(1):155-60.

55. Deschler DG, Walsh KA, Friedman S, Hayden RE. Quality of life assessment in patients undergoing head and neck surgery as evaluated by lay caregivers. Laryngoscope. 1999;109(1):42-6.

56. Wennman-Larsen A, Tishelman C, Wengstrom Y, Gustavsson P. Factors influencing agreement in symptom ratings by lung cancer patients and their significant others. J Pain Symptom Manage. 2007;33(2):146-55.

\section{Publisher's Note}

Springer Nature remains neutral with regard to jurisdictional claims in published maps and institutional affiliations.

\section{Ready to submit your research? Choose BMC and benefit from:}

- fast, convenient online submission

- thorough peer review by experienced researchers in your field

- rapid publication on acceptance

- support for research data, including large and complex data types

- gold Open Access which fosters wider collaboration and increased citations

- maximum visibility for your research: over $100 \mathrm{M}$ website views per year

At BMC, research is always in progress.

Learn more biomedcentral.com/submissions 